\title{
Hydroponics Fodder Grow Chamber
}

\section{Sandip S. Turakne, Shubham B. Jondhale, Prasad M. Vikhe, Mahesh N. Gore}

Department of Electronics and Telecommunication Engineering, Pravara Rural Engineering. College, Loni, India

\begin{abstract}
Article Info

Volume 8, Issue 3

Page Number : $383-387$

Publication Issue :

May-June-2021

\section{Article History}

Accepted : 10 June 2021

Published: 15 June 2021

India is a developing country, but rural areas do not seem to be developing much. Basically most of the public is farmers, most of the farmers have limited agricultural land and also lack of water resources. in many parts of India rain and is not enough for traditional way farming. To avoid these problems our proposed system is structured a helpful touch of fresh and raw feed for cattle food within affordable natural conditions. This hydroponic system does not require any soil to grow fodders and will absorb $80 \%$ less water as compared to the traditional method of farming. Greater topic for work to upgrade the Hydroponic Fodder Grow room for proper management of cattle fodder in any period during the year. This paper suggests a clever plan no human power or less human power is required for It performance. this is usually a completely automated system. In seven to for eight days the room provides fodder as a ready-to-feed product any cattle or grass-eating animals. This process is aided by a Moisture sensor to produce a certain amount of water. Forage seeds use H2O, or solutions that enrich the nutrients of the drug food within the absence of soil. The amount of water is additionally calculated by microcontroller atmega328p. Also, we visit the average temperature and humidity of our room. This heat and humidity are the same and is controlled by a cool cooler and UV/LED light inside the room. Adequate water management and nutrients within the hydroponic system, moisture, humidity $\mathrm{pH}$, water level and temperature should be measurement Using a microcontroller all these functions do it automatically and display at the top of the guided screen. These hydroponics require less space, and this is true usually inside a room of aluminum or fiber. that the environment of the room is completely controlled. That's the fodder prepared for use within 8 days up to 1 fit This healthy cattle fodder. Mainly more production we use maize as fodder. Performing remote monitoring of fodder extension procedure, prohibited by employees, thereby reducing the manual process. Keywords : Monitoring, Atmega Microcontroller, DHT11 (Temp. \& humidity sensor), Moisture Sensor, Controlled Light, Cooling System.
\end{abstract}




\section{INTRODUCTION}

Green fodder is a natural animal feed. Its production to meet this need has been a good challenge among livestock farmers. for many reasons, green food production has been The big problem, then the livestock product. due to the proliferation of a powerful system of livestock rearing, the need for green fodder great. because the gap between demand and supply green fodder is invincible, Researchers and subsistence farmers to find $\mathrm{i}$ another fodder or method of producing that fodder it can restore fodder production and livestock. Hydroponics is what modern technology has reversed the change in green fodder production within the 21st a hundred years. Hydroponics can be a way to grow green fodder without soil in a controlled environment houses or equipment. Many livestock farmers belong to them switching to hydroponic fodder production from common methods of production, for fodder produced in this way is very nutritious, provide sustainable year-round sheep production once save water. Although this method has made way for positive impact within the fodder production system, most of farmers face some difficulties for profit using a hydroponic machine to obtain stable fodder production.

\section{LITERATURE SURVEY}

Muhammad E. H. Chowdhury, Amith Khandakar, Saba Ahmed, Fatima Al-Khuzaei, Jalaa Hamdalla,Fahmida Haque, Mamun Bin Ibne Reaz, Ahmed Al Shafei and Nasser Al-Emadi [1] designed a paper on "IoT Based Construction, Construction and Testing Automated Indoor Vertical Hydroponics Farming TestBed in Qatar "with this paper using this process IoT to do plowing inside the pipes in a desurt area e.g.
Qatar. Kunyanuth Kularbphettong, Udomlux Ampant, also Nutthaphol Kongrodj [2] designed the paper in "An Automated Hydroponics System is supported by Phon Application "in Thailand.In this study, the researcher aims to create ease and productivity for users who should grow hydroponic vegetables using IoT as well moved to automatically control and monitor file default hydroponics vegetable system. The system can check and replenish nutrients by selfregulation displays a graphical interface to manage and manage easily it. Shreya Tembe, Sahar Khan, Rujuta Acharekar [3] formulate a paper on "IoT based Automated Hydroponics The system "in the middle of this page shows a small print of hydroponics used using an electric circuit, water and nutrient solution which means soilless. The program it automatically provides the nutrients and nutrients it will have surveillance. Alejandro Isabel Luna Maldonado, Julia Mariana Márquez Reyes, Héctor Flores Brenced, Humberto Rodríguez Fuentes, Juan Antonio Vidales Contreras and Urbano Luna Maldonado [4] designed the paper in "Hydroponic Automation and Robotics System "in this case point out to future engineers that find acid levels of solution $\mathrm{pH}$, viscosity, oxygen and some things change. long-term work will be collect natural data, available from sensors and the incorporation of man-made intelligence into robots and in hydroponics systems. P Sihombing, N A Karina, JT Tarigan and M I Syarif [5] designed a paper on "Automated hydroponics nutrition plant systems use arduino you have a microcontroller based on android "An automated hydroponic irrigation system using Arduino Uno Microcontroller supported by Android is presented by this paper. Nutritious water flow system through the sensor range to be effective done. The water level inside the hydroponic tube is normal prepared in accordance with the hydroponic requirement, too this can be done as a basic irrigation guide or not. 


\section{SYSTEM MODEL OF PROPOSED SYSTEM}

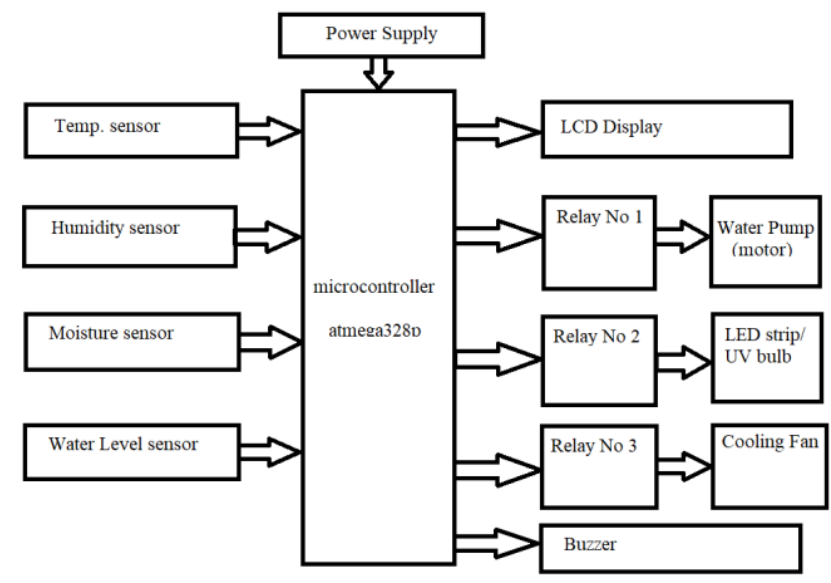

Fig. 3.1 : Block Diagram of proposed system

For our system we use room for average size $1 x 1$ feet. We use fully automatic an electronic system for growing hydroponic fodder in just 7 days. We use the microcontroller atmega328p to to change the system. In that program we use one water truck, single-lead / uv tube, double transmission, 5volt power supply (we create power supply to pcb), cooling fan, moisture sensor, heat sensor, moisture sensor, and specific line material for building a room.

Hydroponics fodder production includes plant growth without soil but in water or nutrient rich Solution in greenhouse (hi-tech devices or low prices) of short duration (approximately 7 days). Nutrition consumption The solution for growing fodder for hydroponics is not it is important and only tap water can be used. India, corn grain should be a means of production hydroponics fodder. Hydroponics green fodder looks as a mat $20-30 \mathrm{~cm}$ long containing roots, seeds and plants. Producing one kilogram of fresh hydroponics cornforage (7-d), 1.50-3.0 liters of water is required. Filling 5-6 folders with new base and 11 DM content- $14 \%$ is common in hydroponics corn fodder, however, Up to $18 \% \mathrm{DM}$ content has also been identified.
How to work In our system we use a room size $1 x 1$ feet. We use a fully automated electronic magnification system a hydroponic fodder in just 7 days. We use microcontroller atmega328p to automate the system. In for that system we use one water truck, one line / led UV tube, two transmissions, 5volt power supply (we create power feed in pcb), cooling fan, humidity sensor, temperature sensor, moisture sensor, and some line material $t$ form room. Production of hydroponics fodder involves plant growth without soil but in water or nutrient rich Solution in greenhouse (hitech devices or low prices) of short duration (approximately 7 days). Nutrition consumption The solution for growing fodder for hydroponics is not it is important and only tap water can be used. India, corn grain should be a means of production hydroponics fodder. Hydroponics green fodder looks as a mat $20-30 \mathrm{~cm}$ long containing roots, seeds and plants. Producing one kilogram of fresh hydroponics corn forage (7-d), 1.50-3.0 liters of water is requiredFilling 5-6 folders with new base and $11 \mathrm{DM}$ content- $14 \%$ is common in hydroponics corn fodder, however, Up to $18 \% \mathrm{DM}$ content has also been identified. The hydroponics fodder is very tasty, it also digests nutritious while transferring other health benefits to animals. The cost of seeds contributes about $90 \%$ of the total cost of producing hydroponics corn fodder. Icon It is recommended to add about 5$10 \mathrm{~kg}$ fresh hydroponics corn fodder per cow per day. However, sprouts half of the corn of the mix mixture in hydroponics fodder production requires no additional corn. Feeding hydroponics fodder increases nutrient digestion of an assignment we cannot contributing to increasing milk production (8$13 \%)$. In cases, where normal green fodder will not be available grown successfully, hydroponics fodder can be made by farmers to feed their dairy animals using the lowest device costs. Hydroponics fodder is very tasty, it is digested and healthy while transmitting another life benefits to animals 
IV. DC POWER SUPPLY



Fig: Block diagram of regulated DC power supply

This work uses a transformer to lower the position input AC power up to $12.5 \mathrm{~V}$ AC.

This region is designed for incoming electricity of 240VAC. If $110 \mathrm{VAC}$ is required, $110 / 12.5$ a power converter should be used.

Step down AC voltage and adjusted using diode bridge. Adjusted DC power is smoothednusing a 2,200uF / 50V electrolytic capacitor

\section{OBSERVATION}

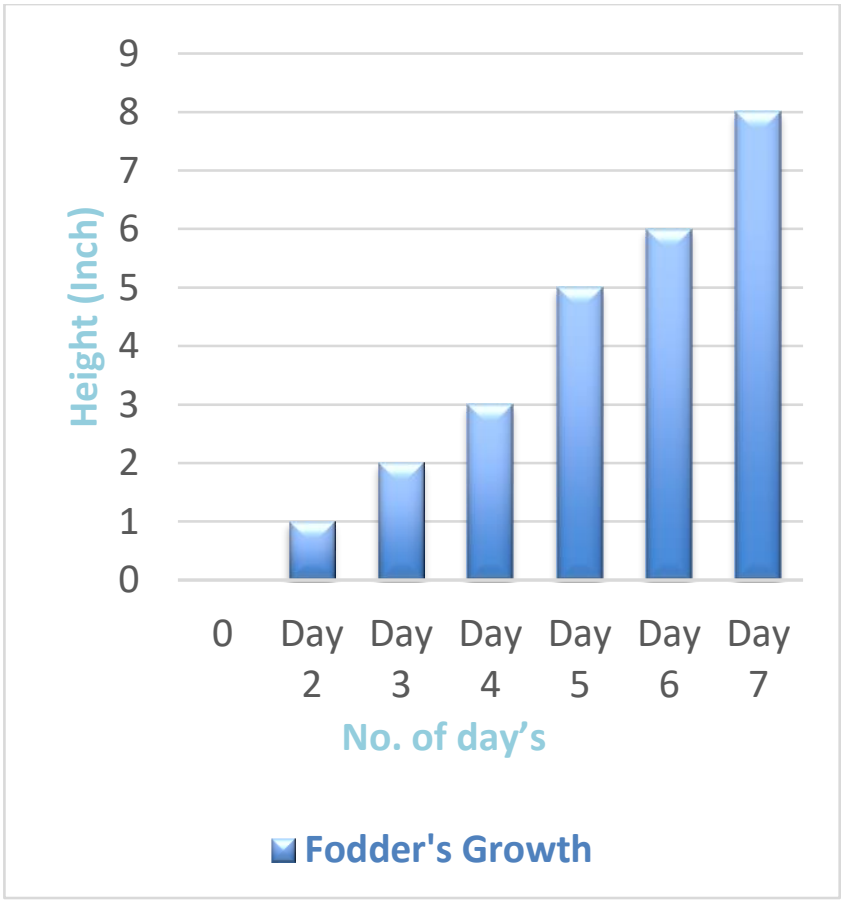

Fig 5.1: Fodder Growth Observation Graph of HFGC
VI. RESULT

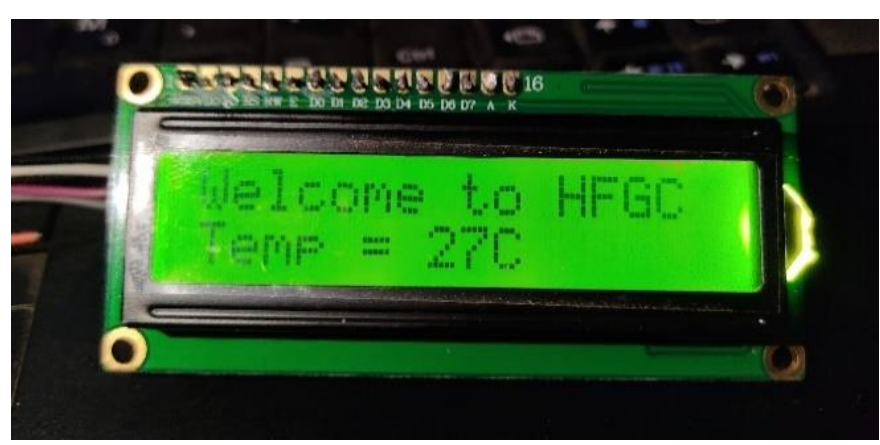

Fig 6.1: Internal Temperature Of HFGC

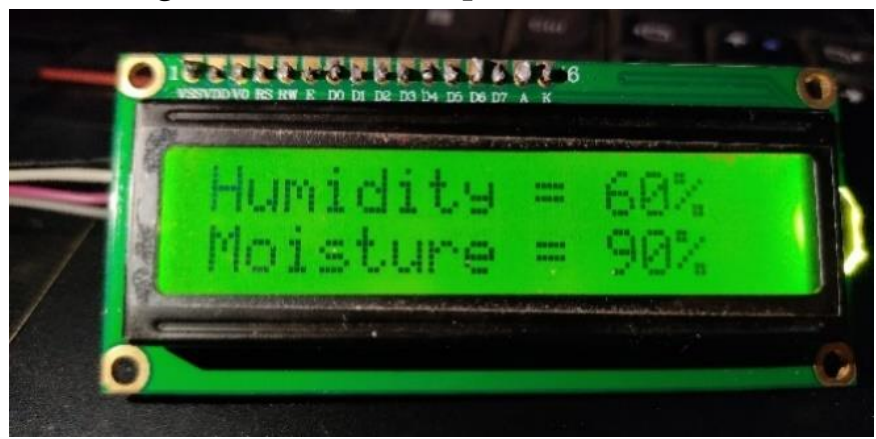

Fig 6.2 : Moisture and Humidity of HFGC

\section{ADVANTAGES}

- Waste No need of Soil and more space.

- It is full on automatic.

- No Need of Manpower.

- It is organic, No need of execs fertilizers.

- More amount of nutrients, its supplementary fodder.

\section{APPLICATION}

- Any cattle farmer can use this to improve the milk production, productivity, and health of the cattle.

- In desert area hydroponics system is best.

\section{CONCLUSION}

HFGC will be very helpful to those who are new in farming, those who don't have that much time to observe crops frequently. According to automation 
artificial farming is the best alternative to natural farming in the future.

\section{REFERENCES}

[1]. Muhammad E. H. Chowdhury, Amith Khandakar , Saba Ahmed, Fatima Al-Khuzaei , Jalaa Hamdalla , Fahmida Haque , Mamun Bin Ibne Reaz , Ahmed Al Shafei and Nasser AlEmadi .2020 "Design, Construction and Testing of IoT Based Automated Indoor Vertical Hydroponics Farming Test-Bed in Qatar"-

[2]. Alejandro Isabel Luna Maldonado, Julia Mariana Márquez Reyes, Héctor Flores Breceda, Humberto Rodríguez Fuentes, Juan Antonio Vidales Contreras and Urbano Luna Maldonado 2019.Automation and Robotics Used in Hydroponic System

[3]. Kunyanuth Kularbphettong, Udomlux Ampant, and Nutthaphol Kongrodj 2019.“An Automated Hydroponics System Based on Mobile Application"in Thailand.

[4]. Shreya Tembe, Sahar Khan, Rujuta Acharekar 2019."IoT based Automated Hydroponics System"

[5]. Alejandro Isabel Luna Maldonado, Julia Mariana Márquez Reyes, Héctor Flores Breceda, Humberto Rodríguez Fuentes, Juan Antonio Vidales Contreras and Urbano Luna Maldonado .2018 "Automation and Robotics Used in Hydroponic System"

[6]. P Sihombing, N A Karina, J T Tarigan and M I Syarif .2018 "Automated hydroponics nutrition plants systems using arduino uno microcontroller based on android"

[7]. Brownin, D.A. 2017. Hydroponic fodder systems.

[8]. Anonymous. 2008. Grass fodder by hydroponics in 8 days.

[9]. Appleman, R.D. 1962. Hydroponic grass for dairy cattle. Agronomy Notes. 3pgs. Retrieved 27.10.2017

\section{Cite this article as :}

Sandip S. Turakne, Shubham B. Jondhale, Prasad M. Vikhe, Mahesh N. Gore, "Hydroponics Fodder Grow Chamber", International Journal of Scientific Research in Science, Engineering and Technology (IJSRSET), Online ISSN : 2394-4099, Print ISSN : 2395-1990, Volume 8 Issue 3, pp. 383-387, May-June 2021. Available at

doi : https://doi.org/10.32628/IJSRSET2183177

Journal URL : https://ijsrset.com/IJSRSET2183177 